\title{
Vulvar contact dermatitis
}

\author{
Cody J. Connor, BS, ${ }^{1}$ Erin E. Eppsteiner, $\mathrm{MD}^{2}$
}

Keywords: Contact dermatitis, allergic dermatitis, irritant dermatitis, contact vulvitis

\begin{abstract}
Contact dermatitis is a common problem in the world of dermatology as well as women's health, where vulvar irritation is a frequent complaint among women. It occurs following exposure to exogenous irritants (irritant contact dermatitis) or allergens (allergic contact dermatitis), and can present in acute, subacute, or chronic forms. While vulvar pruritus and pain can be seen in a number of different conditions, contact dermatitis is one of the most common causes encountered in clinical practice, and its effects on patient quality of life can be dramatic. With a thorough history and a complete physical exam, this prevalent condition can be diagnosed and addressed. Treatment is aimed at identifying and eliminating the underlying cause, restoring the damaged epithelial barrier, and calming the inflammation. Although numerous options are available for addressing the itch and pain, the only true "cure" for contact dermatitis is to avoid the responsible exposures.

${ }^{1}$ University of lowa Carver College of Medicine, lowa City, lowa

${ }^{2}$ University of lowa Hospitals and Clinics, Department of Obstetrics and Gynecology, lowa City, lowa
\end{abstract}

\section{Introduction}

Contact dermatitis is a common problem in the world of dermatology, manifesting as a pruritic or painful rash wherever an offending irritant contacts vulnerable skin. But this condition is not confined to the realm of dermatology; it is also common in women's health, where vulvar irritation is a complaint among many women. Symptoms can be the source of anxiety, fear, and frustration, and as such, they may go underreported to healthcare providers. ${ }^{1}$ Although the presentation of vulvar contact dermatitis shares features with other conditions, a high suspicion, combined with proper clinical and pathological evaluation, is capable of correctly making the diagnosis and allowing for appropriate management.

\section{Vulvar Anatomy and Inherent Susceptibility}

The vulva is the female external genitalia that lie within the anterior perineal triangle, spanning from the mons pubis anteriorly to the perineal body posteriorly and laterally from the inguinal crease to the hymenal ring. The vulva encompasses the labia majora and minora, the clitoral hood, the external urethral meatus, the vaginal introitus, and the greater (Bartholin's) and lesser (Skene's) vestibular glands.

Please cite this paper as: Connor CJ. Eppsteiner EE. Vulvar contact dermatitis. Proc Obstet Gynecol. 2014;4(2): Article1 [ 14 p.]. Available from: http://ir.uiowa.edu/pog/. Free full text article.

Corresponding author: Cody J. Connor, 906 Benton Dr. Apt 22, lowa City, IA 52246; Phone: 563-260-9995; E-mail: codyconnor@uiowa.edu.

Copyright: (c) 2014 Connor \& Eppsteiner. This is an open-access article distributed under the terms of the Creative Commons Attribution License, which permits unrestricted use, distribution, and reproduction in any medium, provided the original author and source are credited. 
The area is comprised of two types of epithelia, which are separated by Hart's line just medial to the labia minora. Lateral to Hart's line, the labia are covered by keratinized epithelium, and medial to this line, the mucosal vulvar vestibule is lined by non-keratinized transitional epithelium. Unlike the rest of the external genitalia, the vestibule is derived from embryonic endoderm (the urogenital sinus) and as such, it morphologically resembles the vaginal mucosa. $^{2}$

Compared to other areas, vulvar skin is exposed to many more physiologic contact irritants including sweat, vaginal secretions, urine, occlusion (by underwear, sanitary pads, skin-skin contact) and mechanical trauma (from sexual activity, scrubbing, etc.). Because the vulva is almost always covered in some way, the degree of occlusion is a unique factor to consider, and the effects can be significant. One consequence may be increased hydration of the skin, as demonstrated by measured elevations in transepidermal water loss $(\mathrm{TEWL}){ }^{3}$ Increased hydration increases the friction coefficient of the vulvar skin and consequently predisposes to mechanical damage. ${ }^{3}$ TEWL is a measure of both hydration and barrier function, and increased values suggest that vulvar skin is not as effective a barrier to water loss as other areas of skin. $^{3}$

TEWL is also related to permeability, which is up to seven times higher in vulvar skin than forearm skin. ${ }^{4}$ Possible contributing factors include a higher concentration of sweat glands and hair follicles, increased cutaneous blood flow, and greater hydration. Similar to the buccal mucosa of the mouth, permeability is particularly elevated in the non-keratinized vulvar vestibule because the absent stratum corneum decreases the barrier function and also decreases the distance necessary for an exogenous substance to traverse. Cells in this area are also more loosely arranged, enabling increased paracellular movement of penetrants. ${ }^{5}$ Thus, vulvar skin is increasingly sensitive to topical agents.

Another unique characteristic of the vulvar epithelium is its hormone responsiveness, particularly to estrogen. The stratum corneum of the labia majora gradually thickens with age until menopause, at which time circulating estrogen levels decline. This leads to tissue atrophy and decreased elasticity, thus impairing the skin's ability to act as a barrier to external exposures. ${ }^{6}$ The elastic degeneration observed in the post-menopausal vulvar dermis is comparable to that which is seen with years of sun exposure and actinic damage in the geriatric population. The drop in estrogen additionally increases the typically acidic $\mathrm{pH}$ of the area and decreases production of lipids: two factors that normally contribute to the skin's protective function. As a result of these changes, the vulvar and vaginal tissues become increasingly sensitive to injury in the post-menopausal population. ${ }^{7}$ Low estrogen states are also observed postpartum and with breastfeeding, certain medications (e.g., birth control, tamoxifen), and removal of the ovaries. Women to whom these apply are thus also at increased risk for developing vulvar contact dermatitis. 


\section{Contact Dermatitis}

Contact dermatitis is a common diagnosis with reported prevalence rates as high as $54 \%$ for patients presenting to vulvar clinics. ${ }^{8}$ It occurs after exposure to exogenous irritants (irritant contact dermatitis) or allergens (allergic contact dermatitis), and can present in acute, subacute, or chronic forms. Severe, acute contact dermatitis can be extremely painful, with associated erosions and bullous lesions. Chronic contact dermatitis may exhibit a milder clinical picture, with simple erythema and irritation, or it could manifest with more pronounced eczematous changes including dry, scaly patches and thick, lichenified plaques with excoriations, fissures, weeping, and possible superimposed infection.

\section{Irritant Contact Dermatitis}

Irritant Contact Dermatitis (ICD) is the most common form of contact dermatitis, ${ }^{9-12}$ although its prevalence is not entirely known. The condition occurs following exposure to substances that have direct cytotoxic effects on keratinocytes, and as such, does not require prior sensitization. These effects can include damage to cell membranes, denaturation of keratin and other proteins, and removal of surface lipids and hydrophilic substances. ${ }^{13}$

With ICD, burning, stinging, and itching are common symptoms, and their severity and rapidity of onset are determined by the potency of the offending agent and the duration/chronicity of exposure. A strong irritant can cause immediate pain, enabling easy recognition of the source, while a weaker irritant may bring about less obvious changes over an extended period, making identification of the offender far more difficult. Because the vulva is generally well-protected with clothing, contact with strong irritants is far less common, but patients with sensory deficits (e.g. quadriplegics) may be unable to recognize when an irritant has penetrated their clothing and is soaking their skin.

The damage caused by contact with irritants can be additive if intermittent exposures are spaced by periods too short to allow for recovery of the epithelium. Individuals with sensitive skin have a lower threshold of cumulative damage necessary for the manifestation of physical signs and symptoms resulting from irritant contact. Besides individual variability in skin sensitivity, other factors also exist to increase risk on an individual basis. Obesity results in occlusion by skin-toskin contact, which enhances moisture production and thus increases friction and resultant mechanical damage. The additional moisture also allows for enhanced permeation of hydrophilic agents into the skin. Friction and hydrophilia are also increased by urinary incontinence, with the added detriment of ammonia exposure to the vulvar skin.

Unlike allergic contact dermatitis, irritant reactions are not typically vesicular or bullous, although the erosions that can occur may give the appearance of compromised vesicles. Involved areas are often symmetric, with sharp demarcations if there is a well-defined area of exposure. As with diaper rash, there is often sparing of the inguinal creases where the offending agent is not as capable of contacting the skin. 
A variety of substances can cause irritant contact dermatitis of the vulva (Table 1), including body fluids such as urine or stool, hygiene products like douches or soaps, or various topical medications. Sodium lauryl sulfate (SLS) is an anionic detergent and surfactant used as a foaming agent in many soaps and shampoos, and it has been implicated in the induction of ICD of the vulva. ${ }^{14}$ Sodium lauryl sulfate has been postulated to contribute to hyperalgesia by inducing proinflammatory cytokines. ${ }^{15}$

\title{
Table 1. Vulvar Irritants
}

\begin{abstract}
Body Fluids: urine (ammonia), feces (enzymes), vaginal discharge, sweat, semen
Feminine Hygiene Products: douches, feminine wipes, sanitary pads/napkins, panty liners, tampons, deodorants, lotions, powders, perfumes, shampoos, soaps

Sexual Support: lubricants, condoms, diaphragms, spermicides, arousal stimulants

Laundry: detergent, bleach, fabric softener

Topical Medicaments: antifungals, anti-itch creams, antibiotics, $\operatorname{Vagisil}^{\mathrm{R}}, \mathrm{A}+\mathrm{D}^{\mathrm{R}}$ ointment, tea tree oil, alcoholbased creams or gels, cantharidin, 5-fluororacil, Imiquimod ${ }^{\mathrm{R}}$, phenol, podophyllin, bichloroacetic acid, trichloroacetic acid

Physical Irritants: tight fitting clothes, nylon, latex, wash cloths, sponges, hot water, excessive washing, vigorous drying with towel, hair dryer (on hot)
\end{abstract}

Table adapted from Margesson, L.J., Contact dermatitis of the vulva. Dermatol Ther, 2004. 17(1): p. 20-7; and Schlosser, B.J., Contact dermatitis of the vulva. Dermatol Clin, 2010. 28(4): p. 697-706.

\section{Allergic Contact Dermatitis}

Unlike ICD, allergic contact dermatitis (ACD) is a type IV delayed hypersensitivity reaction involving antigen-presenting Langerhans cells within the epidermis. These dendritic cells sample and process antigens at the tissue surface and then transport them to lymph nodes where they are presented to $T$ lymphocytes, inducing $T$ cell proliferation and subsequent production of inflammatory cytokines. Because this immune process takes time to progress, physical

Vulvar contact dermatitis manifestations can take 48 to 72 hours to appear following exposure. With such delay before symptom development, the allergen is often difficult for the patient to identify.

Itching is often a prominent feature of $A C D$, which can be somewhat helpful in distinguishing from ICD, in which pain is often a primary complaint, though both symptoms can be present in either disorder. The characteristic appearance of ACD includes erythema, edema, and possible vesicles or bullae with weeping. Because the vulvar skin is thinner, 
edema may be more prominent than in other involved areas. As commonly observed with ACD secondary to poison ivy exposure, vesicles can assume linear or geometric configurations aligning with the direction of allergen spread by the patient's fingers or by contact with a plant. Round patches of dermatitis, for instance, may correspond to the circular motion used to rub in a cream.

Chronic ACD may present more as scaling plaques with varying degrees of erythema, hyperpigmentation, and lichenification, possibly complicated by comorbid lichen simplex chronicus (discussed below). Vesicular responses are less common in African Americans and others of dark complexion, and hyperpigmentation may be so prominent as to overpower any erythema, ${ }^{16}$ so lack of these elements should not distract from the diagnosis. Besides appearance, timing is also important to consider, as intermittent or recurrent itching is a common presentation suggesting episodic exposure to an allergen.

The list of potential allergens is as long as, if not longer than, the extensive list of known vulvar irritants, making the task of identifying the responsible agent just as taxing (Table 2). As with irritants, allergens can be found in soaps, detergents, wipes, and creams. Topical medications and remedies are a significant source of vulvar ACD, and major players include antibiotics (e.g., neomycin), topical anesthetics (e.g., benzocaine), corticosteroids, and herbal extracts. ${ }^{9,17}$ When a patient reacts to a topical medicament, it may not be the particular active agent that's responsible, but rather the preservatives or vehicle of the medication. Examples include parabens in topical antibiotics, and the stabilizer, ethylenediamine, previously used in antifungal creams in the 1970s and 1980s. Added fragrances like balsam of Peru and various others have also been commonly implicated. ${ }^{18}$

Benzocaine is present in many over-thecounter products including Vagisil $^{\mathrm{R}}$ and several preparations for warts and hemorrhoids, meaning patients have ample access to this common allergen and are frequently using it in the vulvar area. Because benzocaine cross-reacts with paraaminobenzoic acid, sulfa drugs, paraphenylenediamine, and aniline dyes, a history of sulfa or hair dye allergy can be helpful in suggesting possible ACD in vulvar patients using this product. ${ }^{19,20}$

Because topical corticosteroids are commonly used to treat a variety of vulvar dermatoses, it's important to keep in mind their potential for inducing comorbid ACD. Positive patch test rates as high as $10.7 \%$ have been reported, with many reacting to multiple different steroids. $^{21}$ Corticosteroids have been classified into four groups (A-D) based on chemical structure and patch test results (Table 3 ), which can help guide management in suspected steroid allergy. ${ }^{17}$ High cross-reactivity exists within each group as well as between Group D2 and Groups A and B. Groups $C$ and D1 demonstrate low crossreactivity with other groups and are less likely to induce ACD. ${ }^{17}$ 


\section{Table 2. Vulvar Allergens}

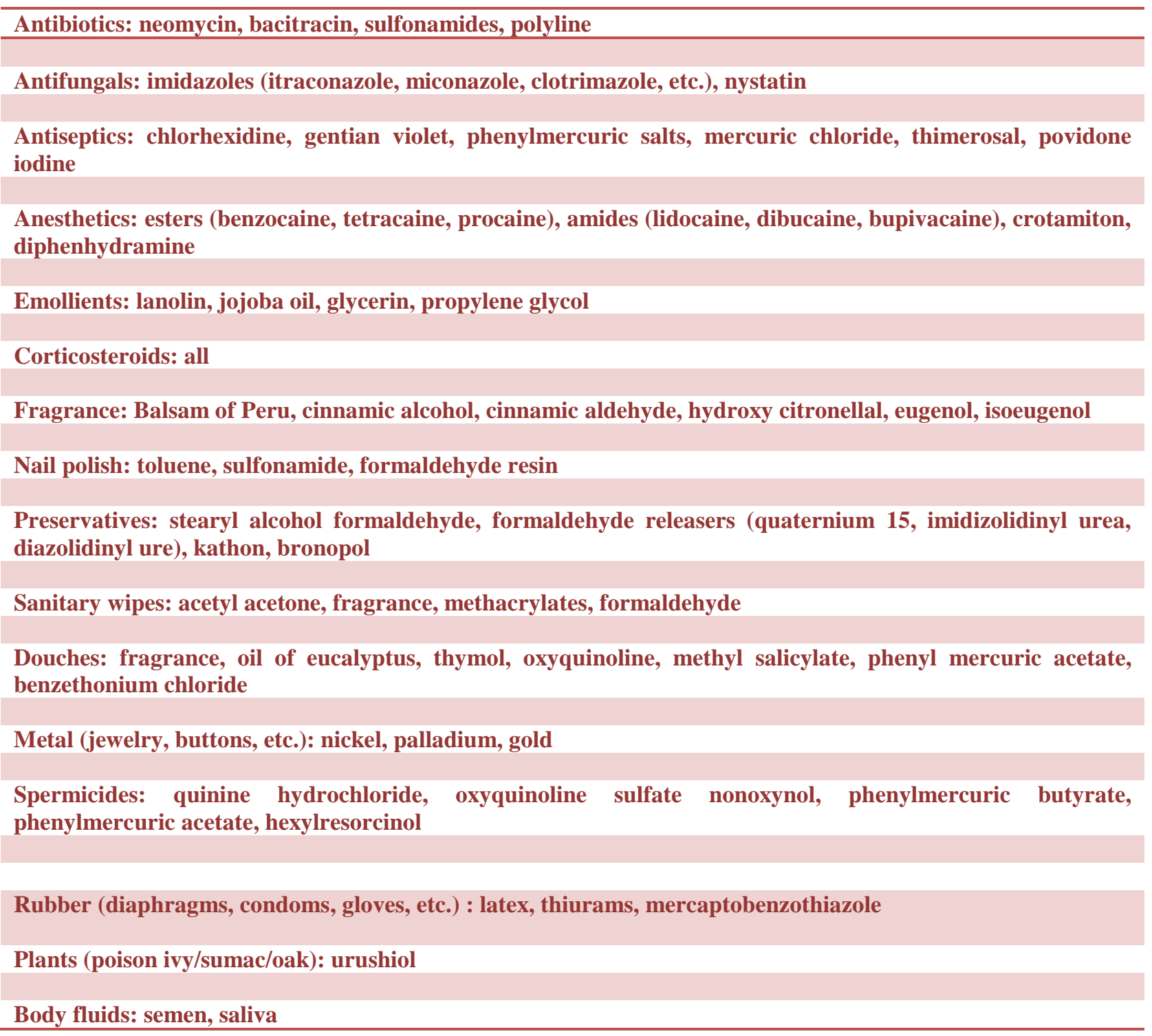

Table adapted from Margesson, L.J., Contact dermatitis of the vulva. Dermatol Ther, 2004. 17(1): p. 20-7; and Schlosser, B.J., Contact dermatitis of the vulva. Dermatol Clin, 2010. 28(4): p. 697-706.

Allergies to metals like nickel can also present in the vulvar region via contact with buttons on clothing, razor blades, or finger transmission after handling jewelry or other external sources. Interestingly, past studies have noted that nickel may also be a component of toilet papers made from recycled paper. ${ }^{9,10}$ Exposures that are unique to the vulva include over-the-counter creams intended for vulvar symptoms or yeast infections (e.g. Vagisil $^{R}$, nystatin, clotrimazole), tampons, sanitary pads, moist wipes, and sexual products 
including various sex toys, lubricants, spermicides, and condoms. ${ }^{22-26}$ Colored dyes can be a source of ACD, with obvious exposure via underwear and more subtle contact occurring through colored toilet paper. ${ }^{27}$

Histopathologically, ACD and ICD are similar and thus pathologic discrimination is often not possible. Given both are treated similarly, confirmation is not clinically necessary.

\section{Lichen Simplex Chronicus}

Lichen Simplex Chronicus (LSC) is a condition that can develop alongside pruritic vulvar contact dermatitis as a direct result of the patient's incessant scratching. Such repeated trauma induces lichenification of the vulvar skin, with a thickened appearance, accentuation of skin markings, and scattered excoriations. Once LSC has developed, it causes pruritus even without an alternative source, thus encouraging further scratching and continued worsening of the LSC in what is known as the "itch-scratch cycle." This condition may disturb the appearance of the primary contact dermatitis, turning what may have begun as an erythematous, vesicular eruption into a series of hyperpigmented plaques.

Table 3. Coopman classification of cross-reactivity in topical corticosteroid allergy

\begin{tabular}{ll}
\hline Corticosteroid Group & Examples \\
\hline A & $\begin{array}{l}\text { hydrocortisone (acetate, succinate, phosphate) cortisone, cortisone acetate, } \\
\text { fludrocortisone, methylprednisolone (acetate, succinate, phosphate), prednisone, } \\
\text { prednisolone acetate, tixocortol pivalate }\end{array}$ \\
\hline B & $\begin{array}{l}\text { amcinonide, budesonide, desonide, flunisolide, fluocinolone acetanide, fluocinomide, } \\
\text { halcinonide, triamcinolone, triamcinolone acetonide }\end{array}$ \\
\hline C & betamethasone, desoxymethasone, dexamethasone, paramethasone, fluocortolone \\
\hline D1 & $\begin{array}{l}\text { beclamethasone dipropionate, betamethasone (valerate, dipropionate), clobethasone } 17 \\
\text { butyrate, clobetasol 17 propyonate } \\
\text { fluticasone, mometasone, prednicarbate, hydrocortisone (17 butyrate, } 17 \text { propionate), } \\
\text { methylprednisolone aceponate }\end{array}$ \\
\hline
\end{tabular}

Table adapted from: Coopman, S., H. Degreef, and A. Dooms-Goossens, Identification of cross-reaction patterns in allergic contact dermatitis from topical corticosteroids. Br J Dermatol, 1989. 121(1): p. 27-34. 


\section{Diagnosis}

\section{$\underline{\text { Differential Diagnosis }}$}

The clinical presentations of vulvar ICD and ACD are similar; additionally their clinical features overlap significantly and include a number of inflammatory vulvar dermatoses. The often eczematous appearance of chronic contact dermatitis must be distinguished from conditions like lichen simplex chronicus, seborrheic dermatitis, atopic dermatitis, vulvar psoriasis, lichen sclerosus, lichen planus, and tinea cruris. More concerning possibilities, such as squamous cell carcinoma in situ and extramammary Paget disease must also be considered if the clinical picture is consistent and the involved area more localized. In cases of acute contact dermatitis, where lesions may be more vesiculo-erosive, possible diagnoses may include disorders like bullous pemphigoid, pemphigus vulgaris, Hailey-Hailey disease (benign familial pemphigus), herpes simplex, candidiasis, and erythema multiforme. More commonly, contact dermatitis is a co-existing condition as noted below.

\section{Making the Diagnosis}

The possibility of multiple etiologies is important to bear in mind, as successful treatment may require individual identification of all contributing factors. For instance, a patient with lichen sclerosis may experience an allergic contact dermatitis in response to her topical steroid ointment or her over-thecounter antifungal cream for recurrent yeast infections. This patient may also be an obsessive cleaner who routinely scrubs her vulva with an abrasive washcloth and a caustic, fragrant soap. It is not hard to see how complicated a case of vulvar symptoms can become, and though cases are not always as difficult as this hypothetical example, it's extremely common for the patient to come with no idea about what exposures (and behaviors) might be contributing. In these cases, the astute clinician must act much like a detective to sift through the assortment of possible culprits.

The patient interview is an essential part of the process, and the patient must be probed about any and all possible exposures to the vulvar area, particularly new ones beginning around the time of symptom onset. These include soaps, laundry detergents, sanitary pads, wet wipes, topical creams, ointments, powders, dyes in underwear or colored toilet paper, lubricants, excessively hot water, abrasive washrags, and more. The investigation must also extend beyond the vulva, as potential allergens or irritants can be transferred by the patient's fingers from other areas of the body, such as the face (makeup) or axilla (deodorant), or from the surrounding environment. Significant others should also be included in the questioning, as fragrant body washes or other usual suspects can certainly be transmitted to the patient during sexual activity.

While interviewing the patient may be extremely high yield, sometimes there is little information gained, or often the list is so broad that further workup is needed to narrow the field. Patch testing is one commonly used method of achieving this goal. The physician, usually an allergist, applies a number of patches to the patient's skin, each one containing a potential antigen, and then monitors for local allergic response. 
Tests are best read at 48,72 , and 96 hours. The reaction of the patient's skin informs of any contact allergy for each particular substance, and this can be helpful in identifying the allergen that might be causing the vulvar dermatitis. Even so, causation may not be entirely straightforward when interpreting patch test results in this setting. Concentrations of some preservatives, for instance, may be lower in actual medications than in their respective patch. In such a case, real-world application of the medicament might not exceed the threshold necessary to incite $A C D$, even if the patient had a positive patch test to a preservative component. $^{28}$

If the diagnosis is in question, biopsy and /or culture may be indicated. As noted, contact dermatitis may be part of a multi-factorial process. Secondary infection with bacteria, viruses, or fungi can occur, and clinical manifestations include fissuring, crusting, and pustules.

\section{Management}

Treatment of vulvar contact dermatitis can be quite difficult, involving several different medical disciplines including dermatology, gynecology, psychology/psychiatry (for emotional and sexual support), and physical therapy (if secondary pelvic floor muscle spasms are present). ${ }^{1}$ The first step in treatment-and sometimes the most difficult for the patient-is to eliminate all potential offending exposures. This often involves making dramatic changes in the patient's daily routine, shopping habits, and sexual practices, and the anxiety produced by this large-scale disruption can serve as a significant barrier to patient compliance. Such a response should be anticipated and addressed at the outset of treatment and periodically thereafter in order to ensure the best chance for improvement.

\section{Vulvar Skin Care}

The goal of vulvar skin care guidelines is to decrease vulvar contact with known irritants, including chemical products, natural moisture, friction, and occlusion. Recommendations are broadly spanning, including changes in clothing, laundry, bathing, hygiene, and birth control options. Patients should be advised to avoid tight-fitting clothes, pantyhose, and synthetic materials (opt for pure cotton underwear), and try to sleep without underwear to avoid nighttime occlusion. Patients should cease use of dryer sheets, fragrant soaps and detergents, and dyes.

When showering or bathing, hot water should be avoided, as this can cause excess irritation. The vulva should be washed gently with one's hands (no washcloths or sponges), using only water (no soap), and should be dried only by patting with a towel or with a hair dryer on its cool setting (no rubbing). The patient should not shave the vulva, as this can cause irritation and epithelial compromise. Trimming/clipping is another alternative that is preferred over the more direct skin contact with razor use.

Common lubricants, including those found in lubricated condoms, should be avoided and replaced with more natural substitutes, like olive oil, vegetable oil, or coconut oil. Vaseline or zinc oxide ointment can be used on the vulva to protect from exposures such as urine, 
blood, or natural moisture. If excessive dampness is an issue, powders like Gold Bond or Zeasorb can be sprinkled in the underwear once or twice a day, though fragrant options like baby powder, or those containing cornstarch, should be avoided.

Adherence to these guidelines is intended to eliminate the offending agent (amongst the number of potential suspects that are simultaneously removed) and result in symptom improvement. Following clinical resolution of the contact dermatitis, individual exposures can be reincorporated one-at-a-time, in a monthly manner, to enable correlation with a particular irritant/allergen if symptoms recur.

\section{Medical Treatment}

The symptoms of contact dermatitisburning and itching - are usually the main source of patient distress. As such, symptom control should be a top priority to ensure patient satisfaction and allow for the appropriate state of mind with which to pursue the lifestyle changes necessary for cure.

To address unremitting pruritus, overthe-counter antihistamines may be useful for some patients. ${ }^{29}$ A practical regimen could include a non-sedating antihistamine-like cetirizine $\left(\mathrm{Zyrtec}^{\mathrm{R}}\right)$, fexofenadine $\left(\right.$ Allegra $\left.^{\mathrm{R}}\right)$, or loratadine $\left(\right.$ Claritin $\left.^{\mathrm{R}}\right)$-in the morning, and a more sedating option-like diphenhydramine $(\text { Benadryl })^{R}$ ) or hydroxyzine (Vistaril ${ }^{R}$, Atarax ${ }^{R}$ - at night, to support restful sleep. Control of itch is not only important for patient comfort but may also be instrumental in improving the dermatitis by decreasing mechanical damage from scratching and by breaking the itch-scratch cycle that may be fueling comorbid LSC.

For pain, the patient may first try acetaminophen or NSAIDs. Topical application of petrolatum or zinc oxide, while recommended mostly as a skin protectant, may also confer a soothing effect for some patients. Twice-a-day sitz baths and cold compresses can mitigate both pain and itch, though cold compresses must not be placed in the freezer, to avoid frostbite.

In situations of recalcitrant pain, practitioners have turned to painmodulating, systemic medications like tricyclic antidepressants (e.g. amitriptyline, nortriptyline, desipramine) and anticonvulsants (e.g. gabapentin, pregabalin), which may address the neuropathic components of the patient's experience. $^{30,31}$ To minimize side effects, amitriptyline should be started at $5 \mathrm{mg}$ and gradually increased to 150 $\mathrm{mg}$. Drowsiness is one of the possible side effects of amitriptyline, and if it becomes a major issue, desipramine (less sedating) can be substituted with a target dose of $125-150 \mathrm{mg}^{31}$ Selective serotonin and norepinephrine reuptake inhibitors (SNRIs), such as venlafaxine and duloxetine, have also been successfully used for vulvar pain, often in conjunction with an anticonvulsant. ${ }^{31}$ These medications are more commonly used for depression, but they can be used for pain if the less expensive tricyclic class is ineffective. In the US, duloxetine has been approved for use in neuropathic pain and fibromyalgia. ${ }^{32}$

Inflammation should then be targeted, most commonly with the use of topical corticosteroids. In general, ointments 
are preferred over creams, as they are less irritating, better absorbed, and serve additionally as an emollient. To begin, twice daily application of a topical steroid ointment is essential, and potency should be correlated with disease severity. Options include lowpotency hydrocortisone $2.5 \%$, midpotency triamcinolone acetonide $0.1 \%$, and high-potency clobetasol propionate $0.05 \%$ or halobetasol $0.05 \%$. Regardless of the steroid chosen, frequency of use and potency should be weaned as the dermatitis improves, as this will avoid unnecessary thinning of the skin.

In severe cases of contact dermatitis and vesiculo-erosive disease, systemic steroids may be indicated. These can be administered as a 14- to 21-day taper of oral prednisone, given at a dose of 40$60 \mathrm{mg}$ daily or $0.5-1 \mathrm{mg} / \mathrm{kg} /$ day. Alternatively, intramuscular steroids can be given as a single dose of triamcinolone acetonide $1 \mathrm{mg} / \mathrm{kg}$; while this route of administration is less burdensome for the patient, it does not allow for easy discontinuation if negative side effects are encountered. Steroids may also be injected intralesionally for treatment of particularly thick, stubborn plaques or areas of deep inflammation resistant to topicals. ${ }^{1}$ A $1 \mathrm{~mL}$ injection of triamcinolone acetonide $10 \mathrm{mg} / \mathrm{mL}$ can be useful for thinning a lesion, and a second injection may be repeated. If the goal is more anti-inflammatory, 3.3 $\mathrm{mg} / \mathrm{mL}$ (triamcinolone acetonide diluted in saline) is more appropriate. Subsequent injections can be performed at 6-week intervals with careful monitoring for side effects like atrophy or hypopigmentation. ${ }^{1}$

Considering the major role that corticosteroid therapy plays in treating contact dermatitis, it is important to anticipate the side effects and plan for ways to counteract them. With the immunosuppressive effects of both systemic and local steroid treatments, patients are at increased risk for vulvar and vaginal yeast infections. Prophylaxis should be considered and may include addition of an antifungal to topical ointments or use of oral fluconazole 150 mg weekly.

\section{Conclusion}

While vulvar pruritus and pain can be seen in a number of different conditions, contact dermatitis is one of the most common causes encountered in clinical practice, and its effects on patient quality of life can be dramatic. Due to fear and embarrassment, patients often opt to endure symptoms, and their suffering goes underappreciated. However, with thorough interviewing and a complete physical exam, this prevalent condition can be diagnosed and addressed. Treatment is aimed at identifying and eliminating the underlying cause, restoring the damaged epithelial barrier, and calming the inflammation with corticosteroids and other means. While numerous options are available for addressing the itch and pain, the only true cure for contact dermatitis is to avoid the responsible environmental exposures.

\section{References}

1. Beecker J. Therapeutic principles in vulvovaginal dermatology. Dermatol Clin. 2010 Oct;28(4):639-48. doi: 10.1016/j.det.2010.07.001. Epub 2010 Aug 14. PubMed PMID: 20883909. 
2. Thompson IO, van der Bijl P, van Wyk $C W$, van Eyk AD. A comparative lightmicroscopic, electron-microscopic and chemical study of human vaginal and buccal epithelium. Arch Oral Biol. 2001 Dec;46(12):1091-8. http://dx.doi.org/10.1016/S00039969(01)00082-6. PubMed PMID: 11684027.

3. Elsner $\mathrm{P}$, Wilhelm $\mathrm{D}$, Maibach $\mathrm{HI}$. Frictional properties of human forearm an vulvar skin: influence of age and correlation with transepidermal water loss and capacitance. Dermatologica. 1990;181(2):88-91.

http://dx.doi.org/10.1159/000247892.

PubMed PMID: 2242791.

4. Britz MB, Maibach HI, Anjo DM. Human percutaneous penetration of hydrocortisone: the vulva. Arch Dermatol Res. 1980;267(3):313-6. http://dx.doi.org/10.1007/BF00403852.

PubMed PMID:7406539.

5. Guy RH, Potts RO, Francoeur ML. Skin barrier function and the mechanism(s) of percutaneous penetration. Acta Pharm Nord. 1992;4(2):115. PubMed PMID: 1388754.

6. Jones IS. A histological assessment of normal vulval skin. Clin Exp Dermatol. 1983 Sep;8(5):513-21. http://dx.doi.org/10.1111/j.13652230.1983.tb01818.x. PubMed PMID: 6641009 .

7. Summers PR, Hunn J. Unique dermatologic aspects of the postmenopausal vulva. Clin Obstet Gynecol. 2007 Sep;50(3):745-51. http://dx.doi.org/10.1097/GRF.0b013e31 80db96ae. PubMed PMID: 17762422.

8. Fischer GO. The commonest causes of symptomatic vulvar disease: a dermatologist's perspective. Australas $\mathrm{J}$ Dermatol. $\quad 1996 \quad$ Feb;37(1):12-8. http://dx.doi.org/10.1111/j.14400960.1996.tb00988.x.
9. Bauer A, Geier J, Elsner P. Allergic contact dermatitis in patients with anogenital complaints. J Reprod Med. 2000 Aug;45(8):649-54. PubMed PMID: 10986683. PubMed PMID: 8936065.

10. Brenan JA, Dennerstein GJ, Sfameni SF, Drinkwater P, Marin G, Scurry JP. Evaluation of patch testing in patients with chronic vulvar symptoms. Australas J Dermatol. 1996 Feb;37(1):40-3. PubMed PMID: 8936070.

11. Goldsmith PC, Rycroft RJ, White IR, Ridley CM, Neill SM, McFadden JP. Contact sensitivity in women with anogenital dermatoses. Contact Dermatitis. 1997 Mar;36(3):174-5. http://dx.doi.org/10.1111/j.1600-

0536.1997.tb00414.x. PubMed PMID: 9145281.

12. Lewis FM, Shah M, Gawkrodger DJ. Contact sensitivity in pruritus vulvae: patch test results and clinical outcome. Am J Contact Dermat. 1997 Sep;8(3):137-40. PubMed PMID: 9249280 .

13. Willis CM, Stephens CJ, Wilkinson JD. Epidermal damage induced by irritants in man: a light and electron microscopic study. J Invest Dermatol. 1989 Nov;93(5):695-9. http://dx.doi.org/10.1111/15231747.ep12319895. PubMed PMID: 2794551.

14. Elsner P, Wilhelm D, Maibach HI. Sodium lauryl sulfate-induced irritant contact dermatitis in vulvar and forearm skin of premenopausal and postmenopausal women. J Am Acad Dermatol. 1990 Oct;23(4 Pt 1):648-52. http://dx.doi.org/10.1016/01909622(90)70268-M. PubMed PMID: 2146289 . 
15. Petersen LJ, Lyngholm AM, ArendtNielsen L. A novel model of inflammatory pain in human skin involving topical application of sodium lauryl sulfate. Inflamm Res. 2010 Sep;59(9):775-81. doi: 10.1007/s00011010-0189-1. Epub 2010 Apr 1. PubMed PMID: 20358390.

16. Berardesca E, Maibach HI. Contact dermatitis in blacks. Dermatol Clin. 1988 Jul;6(3):363-8. PubMed PMID: 3048818.

17. Coopman S, Degreef $\mathrm{H}$, DoomsGoossens A. Identification of crossreaction patterns in allergic contact dermatitis from topical corticosteroids. $\mathrm{Br} \mathrm{J}$ Dermatol. 1989 Jul;121(1):27-34. http://dx.doi.org/10.1111/j.13652133.1989.tb01396.x. PubMed PMID: 2757954.

18. O'Gorman SM, Torgerson RR. Allergic contact dermatitis of the vulva. Dermatitis. 2013 Mar-Apr;24(2):64-72. doi: 10.1097/DER.0b013e318284da33. PubMed PMID: 23474446.

19. LaBerge L, Pratt M, Fong B, Gavigan G. A 10-year review of $p$-phenylenediamine allergy and related para-amino compounds at the Ottawa Patch Test Clinic. Dermatitis. 2011 NovDec;22(6):332-4. doi: 10.2310/6620.2011.11044. PubMed PMID: 22653006.

20. Davis MD. Unusual patterns in contact dermatitis: medicaments. Dermatol Clin. 2009 Jul;27(3):289-97, vi. doi: 10.1016/j.det.2009.05.003. PubMed PMID: 19580923.
21. Warshaw EM, Schram SE, Belsito DV, DeLeo VA, Fowler JF Jr, Maibach HI, Marks JG Jr, Mathias CG, Pratt MD, Rietschel RL, Sasseville D, Storrs FJ, Taylor JS, Zug KA. Patch-test reactions to topical anesthetics: retrospective analysis of cross-sectional data, 2001 to 2004. Dermatitis. 2008 MarApr;19(2):81-5. DOI: 10.2310/6620.2007.06072. PubMed PMID: 18413108.

22. Bircher $A J$, Hirsbrunner $P$, Langauer $S$. Allergic contact dermatitis of the genitals from rubber additives in condoms. Contact Dermatitis. 1993 Feb;28(2):125$6 . \quad$ http://dx.doi.org/10.1111/j.16000536.1993.tb03368.x. PubMed PMID: 8458216.

23. Eason EL, Feldman P. Contact dermatitis associated with the use of Always sanitary napkins. CMAJ. 1996 Apr 15;154(8):1173-6. PubMed PMID: 8612252.

24. Foote CA, Brady SP, Brady KL, Clark NS, Mercurio MG. Vulvar dermatitis from allergy to moist flushable wipes. J Low Genit Tract Dis. 2014 Jan;18(1):E16-8. doi: 10.1097/LGT.0b013e31828e499f. PubMed PMID: 23760148.

25. Pullen SK, Warshaw EM. Vulvar allergic contact dermatitis from clotrimazole. Dermatitis. 2010 Jan-Feb;21(1):59-60. DOI: $\quad 10.2310 / 6620.2009 .09008$. PubMed PMID: 20137741.

26. Wasilewski C Jr. Allergic contact dermatitis from nystatin. Arch Dermatol. 1970 Aug;102(2):216-7. http://dx.doi.org/10.1001/archderm.1970 .04000080088018. PubMed PMID: 5430317.

27. Braitman M. Contact dermatitis due to colored toilet tissue. AMA Arch Derm Syphilol. 1952 Jun;65(6):727. http://dx.doi.org/10.1001/archderm.1952 .01530250091010 . PubMed PMID: 14922961. 
28. Skinner SL, Marks JG. Allergic contact dermatitis to preservatives in topical medicaments. Am J Contact Dermat. 1998 Dec;9(4):199-201. PubMed PMID: 9810018.

29. Stewart KM. Clinical care of vulvar pruritus, with emphasis on one common cause, lichen simplex chronicus. Dermatol Clin. 2010 Oct;28(4):669-80. doi: 10.1016/j.det.2010.08.004. Review. PubMed PMID: 20883911.

30. Updike GM, Wiesenfeld HC. Insight into the treatment of vulvar pain: a survey of clinicians. Am J Obstet Gynecol. 2005 Oct;193(4):1404-9.

http://dx.doi.org/10.1016/j.ajog.2005.02. 102. PubMed PMID: 16202733.

31. Groysman V. Vulvodynia: new concepts and review of the literature. Dermatol Clin. 2010 Oct;28(4):681-96. doi: 10.1016/j.det.2010.07.002. PubMed PMID: 20883912.

32. Pergolizzi JV Jr, Raffa RB, Taylor R Jr, Rodriguez G, Nalamachu S, Langley $P$. A review of duloxetine $60 \mathrm{mg}$ once-daily dosing for the management of diabetic peripheral neuropathic pain, fibromyalgia, and chronic musculoskeletal pain due to chronic osteoarthritis pain and low back pain. Pain Pract. 2013 Mar;13(3):239-52. doi: 10.1111/j.1533-2500.2012.00578.x.

Epub 2012 Jun 21. PubMed PMID: 22716295.

33. Margesson LJ. Contact dermatitis of the vulva. Dermatol Ther. 2004;17(1):20-7. http://dx.doi.org/10.1111/j.13960296.2004.04003.x. PubMed PMID: 14756887.

34. Schlosser BJ. Contact dermatitis of the vulva. Dermatol Clin. 2010 Oct;28(4):697-706. doi: 10.1016/j.det.2010.08.006. PubMed PMID: 20883913. 